\title{
IOT BASED HOME SECURITY AND AUTOMATION USING GOOGLE ASSISTANT
}

\author{
E.Shirisha1, K.M.V Madan Kumar ${ }^{2}$, G.Swarnalatha ${ }^{3}$ \\ ${ }^{1}$ PG Student, E-Mail ID:sirishaedikoju@gmail.com, \\ ${ }^{2}$ Professor, (madankukunuvi@gmail.com) \\ ${ }^{3}$ PG Student. E-Mail ID: beulahangel81@gmail.com \\ Department of Computer Science and Engineering, TKREC, Hyderabad, Telangana, India.
}

Article History:Received:11 november 2020; Accepted: 27 December 2020; Published online: 05 April 2021

\begin{abstract}
Internet of Things (IOT) is an important technology that affects the internet and communication technology. IOT allows people and objects to be connected anytime, anywhere, in any way/shape and function. Earth's mechanical systems have become very popular in the last few decades and improved living conditions. This project provides the structure and model of an automated earth system. The most important feature is the Raspberry pi, which has an internal Wi-Fi module that allows you to control your device over the Internet. It supports a variety of earth tools, such as energy management systems. Besides, the application is built where the user can control the device using Google Assistant. The IOT project also aims to build a wireless home protection system that uses the ESP32 camera Node MCU module to send alerts to owners if anyone takes a picture of the door and sends it to the owner.
\end{abstract}

Keywords: Home Automation, Raspberry pi, ESP32 camera Node MCU, IFTTT (If This That) Application, Blynk Application, Internet of Things (IOT), Google Assistant, Smartphone.

\section{I.INTRODUCTION}

A home is a place where you dream or want to be in a long day of sorrow. People return home after a day of work. Be a small device/technology that helps them turn off the lights and turn off and play their favorite music to make the earth feel better. This project is a simple pricing system. It uses Google Assistant, IFTTT software, Blynk software, and Raspberry pi Controllers as vital devices, as well as a relay panel. Native language sounds are used to enable Google Assistant. All components are connected to the Internet via Wi-Fi, which allows the system to work on IOT. The IOT project also aims to create a wireless earth care system that uses the ESP32 CAM Node MCU module to send notifications to owners when people stand at the door and take pictures.

It uses the Google Assistant, the Blynk[1] application, the IFTTT [2] application, the Raspberry pi [3], and the ESP32 camera

Node MCU [4] as the major components along with relay board comprising of 4/8 relays. Natural language voice is used to give commands to the Google Assistant [5]. All of the components are connected over the internet using Wi-Fi which puts this system under the IOT [5].

\subsection{Internet of Things (IOT):}

The Internet of Things (IOT) is the environment of physical objects connected to the Internet. By providing more information and new presentation models, IOT streamlines our global operations, allowing us to create new values for our specific needs through a voice response system that takes all devices or devices on earth. Goods that have an IP address and can collect and send data over the Internet without assistance and interference from hands. The system should be affordable, easy to install, easy to use, and simple.

\subsection{Embedded Systems:}

The installed system is designed to perform specific tasks, but not as a purposeful computer. There are realtime limits that must be met for security and reason use; others can simplify system tools to reduce costs and reduce or eliminate operational requirements.

${ }^{*}$ Corresponding author: E.Shirisha ${ }^{1}$ 
The installed system is not a separate device - it is usually installed on the device that manages it. Software written for embedded systems is called software all the time and is stored on a readable disk or convector light. Usually works with computer versions: small keyboard, monitor with little or no memory.

\section{LITERATURE SURVEY}

In recent years, the popularity of earth devices has increased due to efficiency and influence due to the integration and cost of smart phones. Text up and implement relevant IOT information by introducing IOT concepts and foundations in a conscious state.

- Now anyone can connect anywhere, anytime, and build relationships that create good dynamic networks. In this section, they solve the problem if there is a problem with the device connected to the system and the concept of data; use the solution so that the best solution can be found.

- Data communication is a small field of computer science that is used to track systems in big data, such as statistics, machine learning, and database systems. This includes analyzing data and specific words and translating them into important information or knowledge.

- Administrators can access and control all devices that are not connected to each user, but only one user can connect devices to the user. With the help of the Internet of Things (IOT) system, mobile devices and computers can remotely control all the work and activities on earth devices over the Internet.

- It can also be used with voice commands such as Google Voice \& Apple Home Kit to easily monitor your earth for security reasons.

\section{METHODOLOGY}

\subsection{Existing System:}

In the existing system home appliances are controlled by Bluetooth by using 8051 microprocessor. Bluetooth need to be in range of 10-15 meters, so that you can switch ON and OFF any electronic appliance within the range.

\subsection{Proposed System:}

In this planned system, Node MCU is put in with a Blynk application account with the IFTTT web site then adding to Google Assistant for voice commands. In this system we have 2 AC loads (Bulb or Fan) connected to the microcontroller by 2 relays and DC motor connected through the L293D motor driver. Voice command controls the house appliances. PIR sensor is used to detect the persons. It also focuses on building a smart wireless home security system which sends alerts to the owner by using internet cam in case of anyone standing on the doorstep the device capture the photo this is done by using pir sensor and ESP32 CAM Node MCU and it will send that image through email. This system is totally handled by the mobile phone. This project is much cost effective than the products available in market.

\subsection{Block Diagram:}

The main part is Raspberry pi \& Node MCU which has inbuilt Wi-Fi module, which will help in controlling devices over the Internet. It supports a wide range of home automation devices like power management systems. In addition to that, an app would be developed which will allow the user to control their devices using the Google Assistant.

This IOT project also focuses on building a smart wireless home security system which sends alerts to the owner by using ESP32 cam module in case of anyone standing on the doorstep the device capture the photo and send it to the owner. 


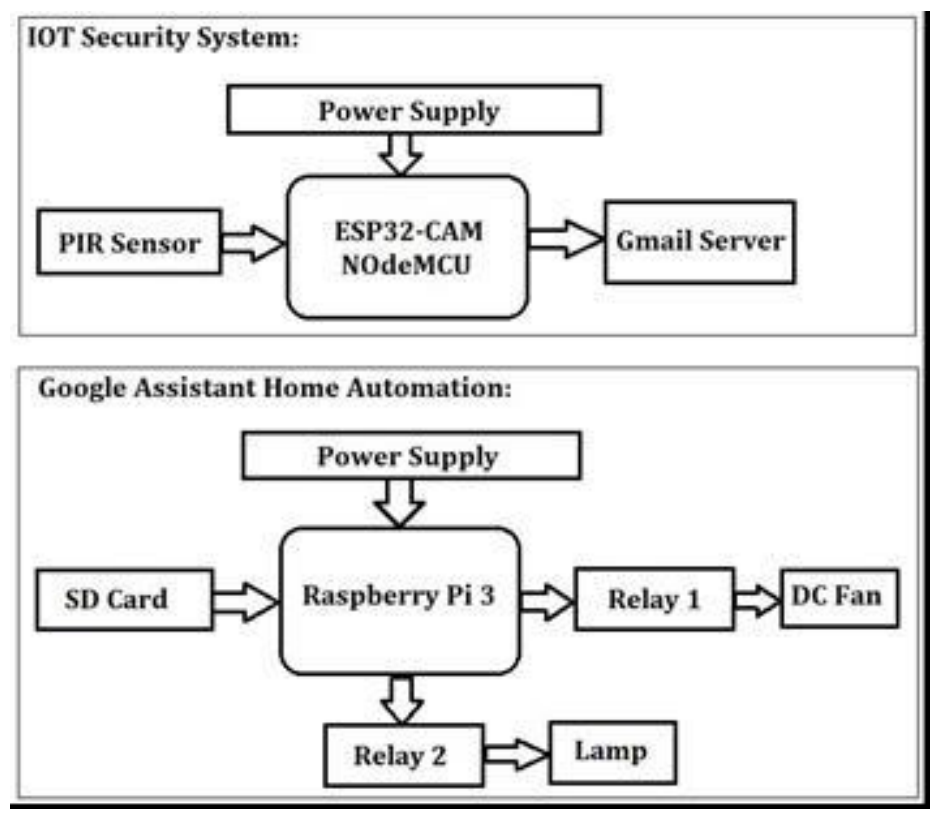

Fig 1: Block diagram of Google Assistant Controlled Home Automation \& IOT Based Home Security

The system design is broken down into two main categories,

i.The hardware- It has the capability to connect to the WiFi module. In hardware, the components are, Raspberry pi, SD card, PIR sensor, power supply, relay module, and ESP32 CAM Node MCU module. ii.The software- The IFTTT module, Raspbian OS and Python languages are used.

\subsubsection{Raspberry Pi:}

Raspberry Pi is a credit card-sized, low-cost but fully functional and programmable computer with modern high-definition multimedia capabilities. It may be the device that gets us back to computing basics. The Raspberry Pi devices looks like a motherboard, with the mounted chips and ports exposed.

Raspberry Pi 3 is used which is installed in the home and all the appliances are attached with it through the relay. It also leads to the development of smaller devices. Computer gets cheaper and smaller in size. Single Board computer (SBC) is a single circuit complete computer with Memory, Input/output (I/O) and different components of computers. Raspberry pi is an example of SBC that is popular and easily available in the market. The Raspberry pi runs a Python program to communicate with each other and control the devices. The aim of the wireless home automation system through voice mainly targets elderly and disabled person. In this paper I will show you how to make webbased Raspberry Pi home automation system that will allow you to control any appliance in your home from anywhere in the world using normal HTTP protocols.

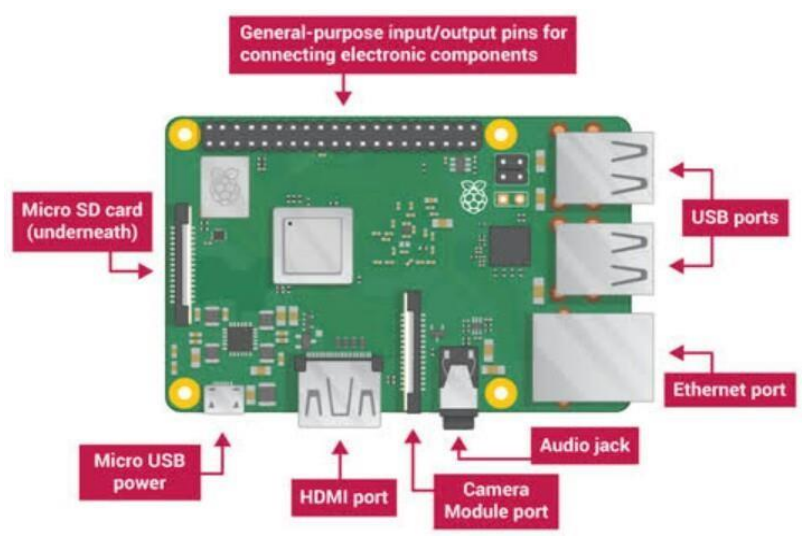

Fig 2: Raspberry pi 


\subsubsection{ESP32 CAM NODE MCU MODULE:}

The ESP32-CAM is a small size, low power consumption camera module based on ESP32. It comes with an OV2640 camera and provides onboard TF card slot. The ESP32-CAM can be widely used in intelligent IOT applications such as wireless video monitoring, Wi-Fi image upload, QR identification, and so on.

The ESP32 CAM Wi-Fi Module Bluetooth with OV2640 Camera Module 2MP For Face Recognition has a very competitive small-size camera module that can operate independently as a minimum system with a footprint of only $40 \times 27 \mathrm{~mm}$; a deep sleep current of up to $6 \mathrm{~mA}$ and is widely used in various IOT applications. It is suitable for home smart devices, industrial wireless control, wireless monitoring, and other IOT applications.

This module adopts a DIP package and can be directly inserted into the backplane to realize rapid production of products, providing customers with high-reliability connection mode, which is convenient for application in various IOT hardware terminals.

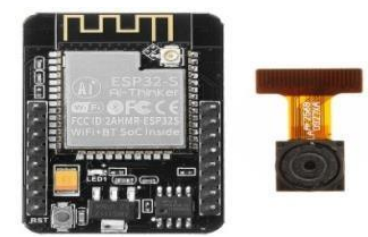

\subsubsection{RELAY BOARD:}

Fig 3: ESP32-CAM NODE MCU MODULE

A relay is an electromagnetic switch. It is activated when a small current of some microampere is applied to it. Normally a relay is used in a circuit as a type of switch, an automatic switch. There are different types of relays and they operate at different voltages. When a circuit is built the voltage that will trigger it has to be considered. In this system the relay circuit is used to turn the appliances ON/OFF. The high/low signal is supplied from the Node MCU microcontroller. When a low voltage is given to the relay of an appliance it is turned off and when a high voltage is given it is turned on.

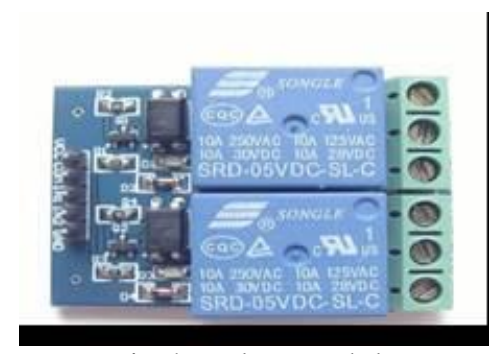

Fig 4: Relay Module

\subsubsection{POWER SUPPLY:}

Aregulated power supply is an embedded circuit; it converts unregulated AC into a constant DC. With the help of a rectifier it converts AC supply into DC. Its function is to supply a stable voltage (or less often current), to a circuit or device that must be operated within certain power supply limits. The output from the regulated power supply may be alternating or unidirectional, but is nearly always DC.

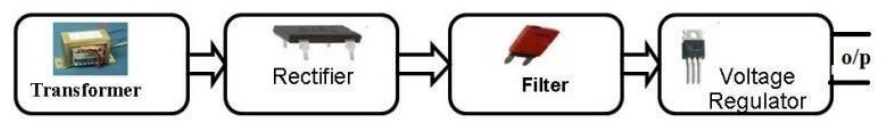

Fig 5: Power Supply

A regulated DC power supply is also called as a linear power supply; it is an embedded circuit and consists of various blocks. The regulated power supply will accept an AC input and give a constant DC output. Figure below shows the block diagram of a typical regulated DC power supply.

\subsubsection{PIR SENSOR:}

PIR sensors are more complicated than many of the other sensors explained in these tutorials (like photocells, FSRs and tilt switches) because there are multiple variables that affect the sensors input and output. To begin 
explaining how a basic sensor works, we'll use this rather nice diagram (if anyone knows where it originates please let me know).

The PIR sensor itself has two slots in it, each slot is made of a special material that is sensitive to IR. The lens used here is not really doing much and so we see that the two slots can 'see' out past some distance (basically the sensitivity of the sensor). When the sensor is idle, both slots detect the same amount of IR, the ambient amount radiated from the room or walls or outdoors.

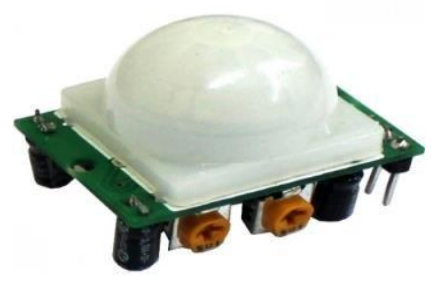

Fig 6: PIR Sensor

\subsubsection{IFTTT MODULE:}

IFTTT derives its name from the programming conditional statement "if this, then that." IFTTT is both a website and a mobile app and has the slogan "Put the Internet to work for you". The idea is that you use IFTTT to automate everything from your favorite apps and websites to appealed accessories and smart devices. What the company provides is a software platform that connects apps, devices and services from different developers in order to trigger one or more automations involving those apps, devices and services. Here, IFTTT application is used to bridge the gap between the Google Assistant commands and the Adafruit app.

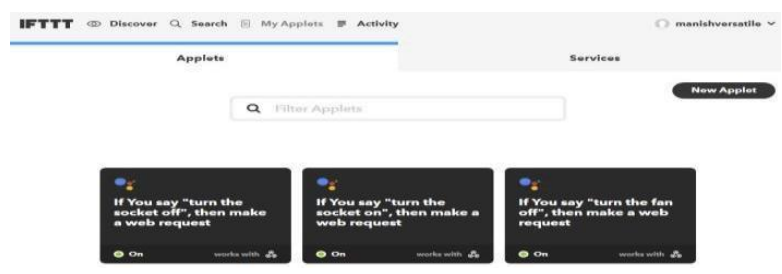

Fig 7: IFTTT Module

\section{RESULTS}

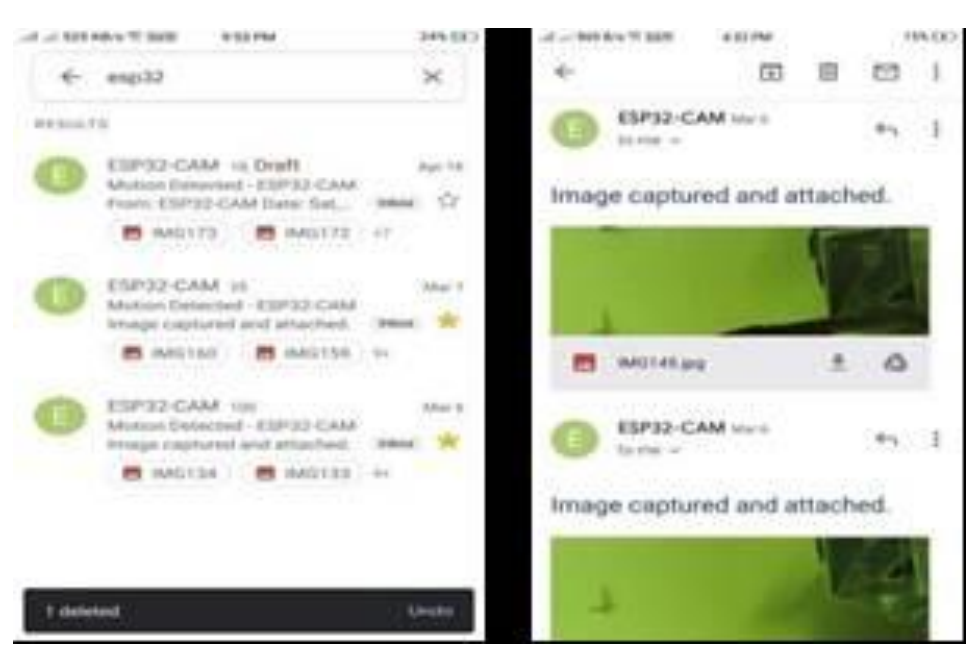




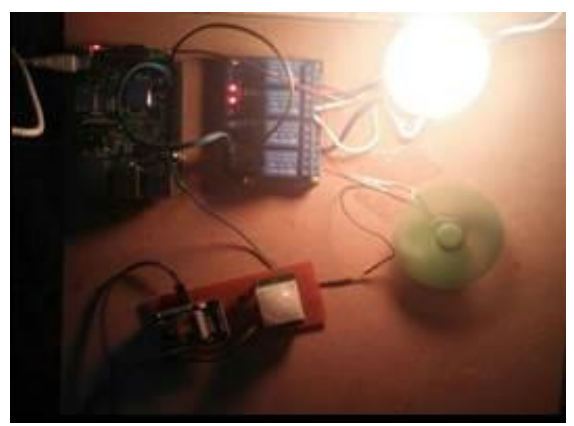

\section{Fig 8: GOOGLE ASSISTANT CONTROLLED HOME AUTOMATATION \& IOT BASED HOME SECURITY KIT}

\section{CONCLUSION}

This system includes an automated home system and voice control in the raspberry pi application and the IFTTT web page and Adult App account and Google Support API. Therefore, users can only use the earth audio and security devices provided by ESP32 CAM Node MCU. According to this system, a smart voice control home automation system is deployed into the Raspberry pi using Adafruit account with IFTTT website and Google assistance API within it. Through which a user can control the home appliances just by giving the voice as input.Google Assistant will simply make the people's lives easy. Because of its enormous usage in the present society implementing this device is dirt cheap. Even though it is a bit complex to implement, the device can be easily made with some time and ability to sort out things that are required. This device is very much useful for people who are physically challenged and visually impaired. It also makes the life of a busy individual easy. This project will reduce the cost and man power required to design an app to control appliances or devices. This project will remove the need of using a smart mobile to control devices. The Raspberry Pi board will also be protected from damages.

\section{FUTERE ENHANCEMENT}

Android apps are also easy to use. Android applications have fire tools that turn on and off the system. You can also add camera modules to the system to increase security. If anyone tries to enter the house, the camera is activated; the person finds and then opens the door. We use grid topology for raspberry pi to merge all files. They can use antivirus software, making it difficult to imagine your system.

\section{REFERNCES}

IFTTT:

https://ifttt.com/discover https://www.pocketlint.com/SmartHome/SmartHom

enew

ESP32 : https://http://esp32.net/

Node MCU:

https://nodemcu.readthedocs.io/en/master https://iotbytes.wordpress.com/nodemcupinout/

Google Assistant: https://assistant.google.com/intl/en_in/

https://www.pocketlint.com/Apps/Appsnews/Googl eapp news

IOT: https://internetofthingsagenda.techtarget.com/definit ion /IOT-device

Application/JSON: https://www.json.org/

Arduino IDE: https://www.arduino.cc/en/Guide/Environment

Wikipedia: https://www.wikipedia.org/

Raspberry pi: https://www.raspberrypi.com 